\title{
Bicuspid Aortic Valve
}

\author{
Blerim Berisha, Xhevdet Krasniqi, \\ Dardan Kocinaj, Ejup Pllana and Masar Gashi \\ Cardiology Department, Internal Clinic, University Clinical Centre of Kosovo \\ Republic of Kosovo
}

\section{Introduction}

Bicuspid aortic valve (BAV) disease is the most common congenital cardiovascular malformation with prevalence of 1-2\% in the human population (Hoffman, 1990; Hoffman \& Kaplan, 2002). Current clinical and scientific studies reveal that bicuspid aortic disease is not a simple valve condition. It increasingly appears to be a genetically based connective tissue disorder. It has been reported that a molecular abnormality in the extracellular matrix may lead to abnormal cell differentiation during valvulogenesis; however, the exact mechanism remains unclear (Nataatmadja et al., 2003; Eisenberg et al., 1995; Fedak et al., 2002). An important problem is that the aorta of patients with BAV is not normal in strength or size. $\mathrm{BAV}$ is frequently associated with other cardiovascular malformations, including aortic root dilatation, aortic stenosis, coarctation of the aorta, and ventricular defects. Although symptoms often manifest in adulthood, there is a wide spectrum of presentations ranging from severe disease detected in utero to asymptomatic disease in old age. Complications can include aortic valve stenosis or incompetence, endocarditis, aortic aneurysm formation, and aortic dissection. Two large contemporary series have demonstrated that the life expectancy in adults with normally functioning BAV is not shortened when compared with that of the general population whereas age and severity of disease were associated with primary cardiac events (Michelena et al., 2008; Tzemos et al., 2008). The risk of aortic dilatation and aortic dissection is higher in patients with BAV than in the general population. In most of patients with BAV, symptoms and physical findings often are absent for many years, whereas the clinical consequences in patients with BAV are associated with regurgitation, endocarditis, and aortic aneurism and dissection. Endocarditis is an important complication for patients with BAV. It occurs particularly in patients with regurgitant or obstructive valves, although the risk of endocarditis may also be high also in hemodynamically stable patients. Prior studies reported significant mortality in patients with infected BAV. However, the last ACC/AHA guidelines recommend that antibiotic prophylaxis is not indicated in young patients and adolescents with BAV (Nishimura et al., 2008).

Patients with moderate valvular dysfunction and normal left ventricular dimensions should be systematically monitored using echocardiography. In adition hypertension should be carefully followed by a cardiologist or cardiac surgeon with specific interest in this valve pathology.

Adequate oral hygiene and antibiotic prophylaxis during dental procedures or when a poor cardiac condition is present are important for preventing endocarditis. Surgery is indicated for severe valvular dysfunction, symptomatic patients, and aortic dilatation. 
This article addresses the embryology, genetic, pathophysiology, clinical presentation, diagnostic procedures, and therapeutic strategies for BAV. In this chapter we will present some cases with BAV with different prognoses from our clinic.

\section{Embryology}

The cardiac structure is evident from the second week of gestation, whereas separation of the heart into four chambers is completed during the sixth and seventh weeks of gestation, resulting in separated systemic and pulmonary circulation. The process of aortic valve morphogenesis begins from the cardiac cushions located in the ventricular outflow tract of the primary heart tube. The pathogenesis of BAV is still unclear. Studies in a Syrian hamster model with a high prevalence of BAV reported that fusion of the right and the left valve cushions is a key factor in the formation of BAV s (Sans-Coma et al., 2006). A previous study suggested that BAV is a consequence of the anomalous behavior of cells derived from the neural crest because BAV often is associated with congenital aortic arch malformations and other neural crest-derived systems (Kappetein et al., 1991). Other studies suggest that extracellular matrix proteins may affect the initiation of cell differentiation during valvulogenesis, while a molecular abnormality in this process may lead to the formation of abnormal cusps (Eisenberg et al., 1995; Fedak et al., 2002).

These abnormalities cause the fusion of two cusps and lead to one larger cusp; therefore, the BAV usually includes two unequally sized cusps, the presence of a central raphe, and smooth cusp margin (Figure 1). A previous clinicopathologic study of a large group surgically excised congenital BAVs showed that raphal position was between the right and left cusp in $86 \%$ of cases (Sabet et al., 1999). An anomalous origin of coronary arteries depends on the spatial orientation of the two cusps. When the orientation of the cusps is anteroposterior, the coronary arteries originate from the anterior sinus or if cusps laterlateral oriented the right coronary artery originate from the common trunk and right Valsava's sinus (Schang et al., 1975). An anomalous origin of coronary arteries may be associated with myocardial hypoperfusion and angina pectoris.

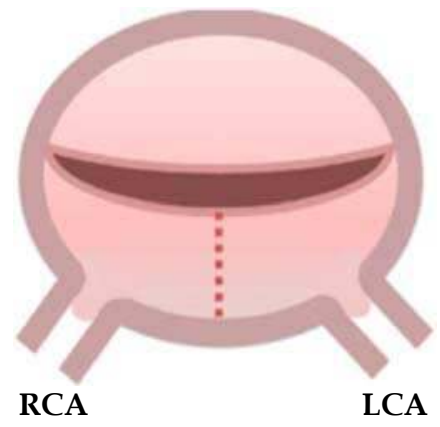

(a) $(86 \%)$

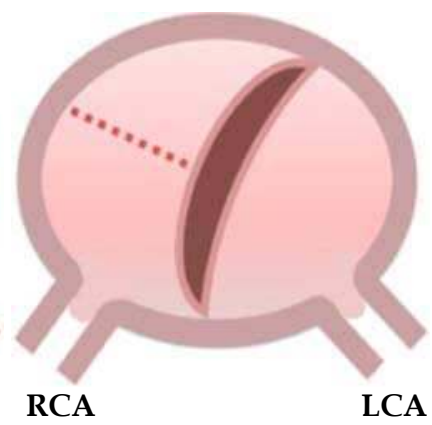

(b) $(12 \%)$

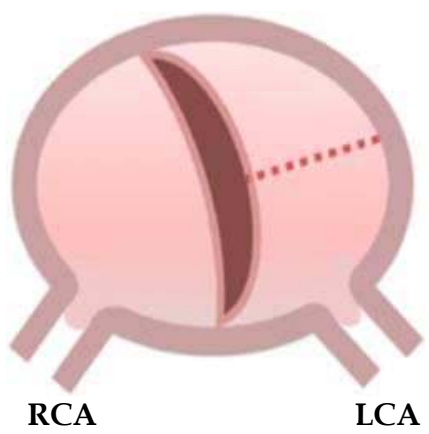

(c) $(3 \%)$

Fig. 1. The morphologic pattern of BAV. (a): Fusion of the right-coronary and left-coronary leaflets. (b): Fusion of the right-coronary and non-coronary leaflets. (c): Fusion of the leftcoronary and non-coronary leaflet. RCA, right coronary artery. LCA, left coronary artery. The red dotted line indicate the raphal position 


\section{Genetics of the bicuspid aortic valve}

$\mathrm{BAV}$ is a complex congenital disease; therefore, its etiology remains unclear, but genetic factors have been proposed. Most BAV s occur as an isolated congenital defect; however, a study on 41 families with a family member having surgically corrected BAV reported the prevalence of BAV to be at least $14.6 \%$ (Emanuel et al., 1978). A much more recent study in 50 probands with BAV concluded that the heritability (h) of BAV was $89 \%$, and suggested that in this population, BAV is almost entirely genetic (Cripe et al., 2004). Two studies have identified genomic regions responsible for cardiovascular congenital disease associated with BAV. The first genetic cause of BAV is Anderson syndrome, which is reported to be a result of mutations in the KCNJ2 gene, whereas it clinically presents as ventricular arrhythmias, periodic paralysis, and scoliosis (Andelfinger et al., 2002). Another study in a large family with autosomal-dominant aortic valve disease diagnosed using genome-wide linkage analysis suggests that NOTCH1 gene mutations mapped to chromosome 9q-34 are responsible for the early developmental defect in the aortic valve (Garg et al., 2005). These studies are very important for understanding the complex etiology of congenital valvular disease, and they may help us to develop novel therapeutic strategies for preventing and treating BAV.

\section{Congenital cardiovascular syndromes associated with bicuspid aortic valve}

\subsection{Coarctation of the aorta}

It has been reported that BAV is presented in $>50 \%$ of patients with coarctation of the aorta (COA) (Duran et al., 1995). Patients with COA and BAV are reported to have more severe disease associated with aortic stenosis, aortic regurgitation, and aortic aneurysm. The risk of dissection of the aorta and death is greater when COA and BAV are comorbid (Abbott, 1928). Microfibrilar proteins such us fibrillin -1 may be deficient during valvulogenesis, which could reduce the structural integrity both in the aortic valve and aorta. Aortic dysregulation is associated with increased activity of metalloproteinases, which may have impact on fibrillin-1 (McMillan ,et al., 1997).

\subsection{Turner syndrome}

Turner syndrome characterized by a defect in or the absence of one $\mathrm{X}$ chromosome. Except for gonadal dysgenesis, cardiovascular defects are commonly present in this group of patients. Clinical research on patients with Turner Syndrome reports that BAV is present in $30 \%$ of cases, that over $95 \%$ of BAV s result from fusion of the right and left coronary leaflets, and that aortic ascending diameters are significantly greater in this group of patients (Miller et al., 1983; Sachdev et al., 2008).

\subsection{Patent ductus arteriosus}

Patent ductus arteriosus is usually obliterated during the first month of life (Mitchell, 1957; Reller et al., 1988; Mandorla et al., 1990; Lim et al., 1992). Patent ductus arteriosus is usually present in pediatric patients with BAV and may be associated with hand anomalies (Gelb et al., 1999).

\subsection{Williams syndrome}

Williams Syndrome is arteriopathy characterized by supravalvular aortic stenosis which may be associated with COA, renal artery stenosis, and arterial hypertension. Williams 
syndrome has also been associated with complete atrioventricular septal defect (Nakamoto et al., 2003), and is reported to be commonly present in patients with BAV (Sugayama et al., 2003; Hallidie-Smith \& Karas, 1988).

\subsection{Ventricular septal defect}

Ventricular architecture may be characterized by complex malformation during embryogenesis involving both septation and valve formation. Ventricular septal defects are often associated with BAV and other complex congenital malformations (OppenheimerDekker et al., 1985) . BAV is reported to be present in up to $30 \%$ of adult patients with small ventricular septal defects (Neumayer et al., 1988). However, BAV may also be associated with large ventricular septal defects and poor clinical outcome (Berisha et al., 2009).

\section{Pathophysiology}

Valve leaflet morphology and orientation are competent for pathophysiology of left heart. Adhesions of commissures and cusp calcifications predisposes to eventual stenosis, hemodynamically presented by different pressures between left ventricle (LV) and the ascending aorta during the systolic and diastolic period. Aortic stenosis is the most common complication of BAV, whereas aortic regurgitation is reported to be present in $13 \%$ of cases (Sabet et al., 1999). Turbulent flow along the abnormal structure of the BAV leads to fibrotic changes and stenotic progression. The pressure differences in stenotic patients with BAV are important because deviation from normal flow can cause important changes, in both the LV and the ascending aorta. High LV pressure in BAV increases wall stress, which results in the generation of concentric ventricle hypertrophy. Previous studies suggest that mechanical stimuli of myocytes can induce ventricular hypertrophy by specific gene expression, possibly via protein kinase C activation (Komuro et al., 1991, 1999). Progressively over time, the LV becomes more hypertrophic and less compliant, which contributes to a reduction of LV function. At this point, reduced stroke volume and cardiac output may lead to congestive heart failure. Post-stenotic dilatation may be a result of prolonged and severe aortic stenosis. Abnormal flow along the wall of the aorta can vibrate the vessel wall at different frequencies (Boughner \& Roach, 1971), and may directly modulate elastin, whereas histopathological findings in congenital cardiac syndromes show medial degeneration and decreased fibrillin-1 in the aortic wall (Nataatmadja et al., 2003); however, the exact mechanism causing aortic dilatation in patients with BAV is unclear.

BAV may be associated with abnormal coronary arteries or the coronary ostium may be stenotic (Roberts, 1970), while angina pectoris is reported to be present in patients with severe aortic stenosis and without coronary disease (Julius et al., 1997) .Wall stress during systole and diastole, and impaired LV relaxation in severe aortic stenosis, reduces the coronary flow reserve and causes subendocardial underperfusion; however, the exact mechanisms of angina pectoris in BAV are not very clear.

Aortic regurgitation in patients with BAV is a result of cusp prolapse, fibrotic retraction, or dilatation of the sinotubular junction. BAV tends to become progressively more stenotic or regurgitant over time, and the valve becomes the site of infective endocarditis. Endocarditis is a result of turbulent flow, which induces chronic abrasion and abscess formation. Endocarditis can cause valve destruction and lead to severe aortic incompetence associated with a poor clinical outcome. 


\section{Clinical presentation}

The clinical presentation of patients with BAV can vary from severe valve disease in infancy to asymptomatic valve disease in old age. Disease is more severe and has poor clinical outcomes in infants with BAV comorbid with aortic stenosis (Hastreiter et al., 1963; Moller et al., 1966).

Symptoms are a result of valvular stenosis, regurgitation, endocarditis, and aortic complications such as dilatation and dissection. Symptoms associated with aortic stenosis are angina pectoris, syncope, and congestive heart failure. Stenosis is more rapid if the aortic cusps are asymmetrical or anteroposteriorly oriented (Ward, 2008). Angina pectoris occurs in patients with severe aortic stenosis and in those who do not have coronary artery disease; it may be a result of ventricular hypertrophy.

Syncope is another common symptom in patients with BAV. Syncope reflects the cerebral hypoperfusion caused by the inability to increase stroke volume during physical activity.

The most common complication of aortic stenosis is congestive heart failure symptomatically presented with dyspnea, which is a result of combined diastolic and systolic dysfunction caused by elevated afterload and increased filling pressures.

Aortic regurgitation reported to be more common in young patients and caused by prolapse of the greater cusp, which may associated with aortic root dilatation. Although young patients with BAV often are asymptomatic, echocardiographic studies show that $47 \%$ of this group of patients have some degree of incompetence (Michelena et al., 2008). Aortic regurgitation in patients with BAV carries an increased risk of endocarditis. If a patient with BAV complians of fever, weakness, and chest pain, endocarditis may be present. Endocarditis occurs in $10-30 \%$ of patients with BAV and can lead to valve perforation or destruction (Ward, 2008).

Aortic dilatation and dissection can be echocardiographcally diagnosed in patients with minimal valvular dysfunction even when they are asymptomatic; therefore, the risk of aortic dissection in patients with BAV may be higher than clinical presentation. Aortic dilatation may be progressive and often requires surgical correction (Duran et al., 1990; Sabet et al., 1999).

The clinical presentation in patients with BAV and presence of other cardiac congenital defects depends from structural complexity of the heart. In patients with COA, the presence of hypertension increases the risk of aortic dissection, considering that congenital abnormalities of the aortic wall are also involved. Patient may complain of chest pain, hoarseness, and respiratory difficulties. In adult patients with interventricular septal defects, the clinical presentation depends on the size of the defect area and the grade of aortic stenosis. If the interventricular defect is small, the patient may be asymptomatic, but when the interventricular defect is large, cardiac output will decrease and Eisenmenger syndrome will develop. Eisenmenger syndrome clinically presents with central cyanosis and shortness of breath during physical activity. However, during that the BAV becomes thicker, more fibrotic, and more calcified, and if is not surgically corrected cardiac output will decrease dramatically and may lead to cardiac death.

Two large recent series reported that clinical course of unoperated patients with BAV depends on age, stenosis, and aortic incompetence (Michelena et al., 2008; Tzemos et al., 2008). The severe aortic stenosis, and severe aortic incompetence in older patients increases the risk of primary cardiac events including cardiac death. Both these studies suggest that intervention on the basis of early symptoms or incipient cardiac dysfunction may decreases the mortality of patients with BAV. 


\section{Diagnosis}

\subsection{Physical examination}

A physical examination is very helpful for evaluating the complications of BAV. Munt et al. (1999) reported that the amplitude of the pulse in the carotid artery was a significant predictor of outcome in patients with valvular aortic stenosis. If stenosis is present, the arterial pulse is small or weak and rises slowly, described as "parvus et tardus". The cardiac pulse at the apex initially is normal; however, arterial pulse is delayed and reduced in amplitude if evaluated by palpation of the carotid artery. Auscultatory findings are best heard in the left second intercostal space. The S1 usually is normal but sometimes may be associated with ejection click. The S2 is soft, and when aortic stenosis is present, S2 occurs simultaneously with P2. In aortic stenosis, an ejection systolic murmur is heard in the left second intercostal space but may also be transmitted to the carotid arteries. If aortic incompetence is present, a diastolic murmur of aortic regurgitation may be heard.

\subsection{ECG}

The ECG changes are not specific in patients with BAV: left ventricular hypertrophy, atrial enlargement, and arrhythmias may be present.

\subsection{Echocardiography}

The most important diagnostic method for first detecting and evaluating complications in patients with BAV is echocardiography. A transthoracic echocardiogram (TTE) considered the method of choice for evaluating valvular structure, calcifications, vegetations, cardiac chamber structure, and ejection fraction. Doppler methods are the most common techniques used for evaluating valvular regurgitation. For BAV associated with stenosis, mean gradient and maximal flow velocity should be measured, but when regurgitation is present, the effective regurgitant area (ERO) and Doppler jet size should be evaluated (Quinones, et al., 2002; Zoghbi et al., 2003). Based on recommendations for evaluating the severity of native valvular regurgitation with two-dimensional and Doppler echocardiography, aortic regurgitation is classified as mild, moderate, and severe (Zoghbi et al., 2003). In 2006, ACC/AHA published guidelines for the management of patients with valvular disease in which aortic stenosis classified as mild, moderate, or severe (Table 1). For asymptomatic patients with aortic stenosis, echocardiography is recommended for evaluating disease progression. In asymptomatic patients, TTE recommended: every year for severe aortic stenosis, ever 1-2 years for moderate aortic stenosis and every 3-5 years for mild aortic stenosis (Bonow et al., 2006). Transesophageal echocardiography (TEE) is also very

\begin{tabular}{l|l|l|l|}
\hline Indicator & Mild & Moderate & Severe \\
\hline Jet velocity $(\mathrm{m}$ per second) & $<3.0$ & $3.0-4.0$ & $>4.0$ \\
Mean gradient $(\mathrm{mmHg})$ & $<25$ & $25-40$ & $>40$ \\
Valve area $\left(\mathrm{cm}^{2}\right)$ & $<1.5$ & $1.0-1.5$ & $<1.0$ \\
Valve area index $\left({\left.\mathrm{cm} \mathrm{per} \mathrm{m}^{2}\right)}\right.$ & & $<0.6$ \\
\hline
\end{tabular}

Modified from Bonow et al.,(2006). ACC/AHA Practice Guidelines. Circulation 114, pp. e84-e231.

Table 1. Classification of the severity of aortic stenosis 
important for evaluating the aortic valve and thoracic aorta, whereas the sensitivity and specifity of multiplane technique for assessing aortic valve morphology is high (Alegret et al., 2005; Espinal et al., 2000).

\subsection{Other diagnostic procedures}

In patients with poor acustic window, cardiac magnetic resonance (MR) and multidetector computed tomography (CT) are useful for measuring the aortic valve area and is an alternative method to echocardiography in selected cases (Shelton et al., 2003; Pouleur et al., 2007). MR imaging is an essential method for diagnosing COA and root aneurism.

\section{Endocarditis prophylaxis}

The most common bacteria that causes the formation of perivalvular abscess is Staphylococcus aureus. Indications for antibiotic prophylaxis in patients with BAV are before procedures expected to produce bacteremia; however, new ACC/AHA guidelines recommend that antibiotic prophylaxis is no longer indicated for preventing of infective endocarditis in adolescents and young adults with native heart valve disease (Nishimura et al., 2008). This committee concluded that infective endocarditis prophylaxis for dental procedures is reasonable only for patients with cardiac conditions associated with a high risk of adverse outcomes from infective endocarditis (Table 2).

\begin{tabular}{ll}
\hline Procedures & Antibiotics \\
\hline Dental : & Amoxicillin, Ampicillin \\
Manipulation of gingival tissue & Penicillin allergic: \\
Manipulation of periapical region of teeth & Clindamycin, Cefalexin, Cefadroxil, Cefazolin \\
Perforation of oral mucosa & Azithromycin, Clarithromycin, Clindamycin \\
\hline
\end{tabular}

Prophylaxis is not recommended for patients who undergo a:

- Genitourinary procedure

- Gastrointestinal procedure

Nishimura et al., (2008). J Am Coll Cardiol 52,676-685.

Table 2. Recommendations for antibiotics for endocarditis prophylaxis before procedures

\section{Treatment}

When to surgically treat asymptomatic patients with BAV remains controversial. Sometimes aortic stenosis correlates poorly with clinical presentation; however, if it is combined with regurgitation, symtoms might be present. The risk of sudden death in asymptomatic adult patients with severe aortic stenosis is reported to be less than $1 \%$ per year (Pellika et al., 2005). Bonow et al., (2007) and Iung B et al. (2003) reported that valve replacement is not recommend for asymptomatic patients; however, current practice guidelines recommended aortic valve replacement in patients with reduced left ventricular systolic function $(\mathrm{EF}<50 \%)$ without other explanation even when they are asymptomatic (Table 3). 


\section{Class I}

1. Indicated for symptomatic patients with severe aortic stenosis

2. Indicated for severe aortic stenosis and undergoing $\mathrm{CABG}$

3. Indicated for severe aortic stenosis and undergoing surgery on the aorta and other heart valves

4. Indicated for severe aortic stenosis and LV dysfunction EF less than 0.50

\section{Class II a}

1. Indicated for moderate aortic stenosis and undergoing $\mathrm{CABG}$ or surgery of the aorta and other heart valves

\section{Class II b}

1. Asymptomatic with severe aortic stenosis and abnormal response to exercise

2. Asymptomatic Adults with severe aortic stenosis and rapid progression

3. Mild aortic stenosis, undergoing CABG, rapid progressions

4. Asymptomatic with extremely severe aortic stenosis (when mortality $\leq 1 \%$ )

\section{Class III}

1. AVR is not recommended for preventing sudden cardiac death in patients who have non of the findings listed in IIa and IIb

CABG, coronary artery bypass graft. AVR, aortic valve replacement;

Bonow et al. (2006).

Table 3. Indications for aortic valve replacement in patients with aortic stenosis

\begin{tabular}{|c|c|}
\hline Class I & Class IIa \\
\hline $\begin{array}{l}\text { Patients with bicuspid aortic valve and } \\
\text { dilatation of the aortic root or ascending aorta } \\
\text { (diameter }>4.0 \mathrm{~cm} \text { ) should undergo serial } \\
\text { evaluation of aortic root/ascending aorta size } \\
\text { and morphology by echocardiography, CMR } \\
\text { or CT on a yearly basis. }\end{array}$ & $\begin{array}{l}\text { It is reasonable to give b-adrenergic } \\
\text { blocking agents to patients with BAV } \\
\text { and dilated aortic roots (diameter >than } \\
4.0 \mathrm{~cm} \text { ) who are not candidates for } \\
\text { surgical correction and who do not have } \\
\text { moderate to severe AR. }\end{array}$ \\
\hline $\begin{array}{l}\text { Surgery to repair the aortic root or replace the } \\
\text { ascending aorta is indicated in patients with } \\
\text { BAV if the diameter of aortic root or } \\
\text { ascending aorta is greater than } 5.0 \mathrm{~cm} \text { or if the } \\
\text { rate of increase in diameter is } 0.5 \mathrm{~cm} \text { per year } \\
\text { or more. }\end{array}$ & $\begin{array}{l}\text { CMR imaging or cardiac CT is } \\
\text { reasonable in patients with BAV when } \\
\text { aortic root dilatation is detected by } \\
\text { echocardiography to further quantify } \\
\text { severity of dilatation and involvement of } \\
\text { the ascending aorta. }\end{array}$ \\
\hline $\begin{array}{l}\text { In patients with BAV undergoing AVR } \\
\text { because of severe AS or AR, repair of the } \\
\text { aortic root or replacement of the ascending is } \\
\text { indicated if the diameter of the aortic root or } \\
\text { ascending aorta is grater than } 4.5 \mathrm{~cm} \text {. }\end{array}$ & \\
\hline
\end{tabular}

$\mathrm{CMR}=$ cardiac magnetic resonance, $\mathrm{CT}=$ computed tomography. Bonow et al. (2006).

Table 4. Evaluation and Treatment of Dilated Ascending Aorta in patients with Bicuspid Aortic Valve ACC/AHA 2006 Guidelines for the management of patients with valvular heart disease 


\begin{tabular}{|c|c|}
\hline Risk factor & EuroSCORE Points \\
\hline \multicolumn{2}{|l|}{ Age (years) } \\
\hline$<60$ & 0 \\
\hline $60-64$ & 1 \\
\hline $65-69$ & 2 \\
\hline $70-74$ & 3 \\
\hline $75-79$ & 4 \\
\hline $80-84$ & 5 \\
\hline $85-89$ & 6 \\
\hline $90-94$ & 7 \\
\hline$>95$ & 8 \\
\hline \multicolumn{2}{|l|}{ Sex } \\
\hline Female & 1 \\
\hline Chronic pulmonary disease & 1 \\
\hline Extracardiac arteriopathy & 2 \\
\hline Neurological dysfunction & 2 \\
\hline Previous cardiac surgery & 3 \\
\hline Serum creatinine $>200 \mu \mathrm{M} / \mathrm{L}$ & 2 \\
\hline Active endocarditis & 3 \\
\hline Critical preoperative state & 3 \\
\hline Unstable angina & 2 \\
\hline \multicolumn{2}{|l|}{ LV dysfunction : } \\
\hline LVEF $30-50 \%$ & 1 \\
\hline LVEF $<30 \%$ & 3 \\
\hline Recent $\mathrm{MI}<90$ days & 2 \\
\hline Pulmonary hypertension, PSAP $>60 \mathrm{mmHg}$ & 2 \\
\hline Emergency & 2 \\
\hline Major cardiac procedure other than CABG & 2 \\
\hline Surgery of thoracic aorta & 3 \\
\hline Post- infarct septal rupture & 4 \\
\hline
\end{tabular}

$\mathrm{LVEF}=$ left ventricular ejection fraction, $\mathrm{MI}=$ myocardial infarction, $\mathrm{CABG}=$ coronary artery bypass grafting Roques et al. (1999).

Table 5. Score risk classification in the EuroScore 
Elective surgery in patients with severe stenosis can prevent sudden cardiac death, and irreversible cardiac damage, and decrease operative risk. Coady et al., (1997) reported that the growth rate for the ascending segment of the aorta is 0.1 to $0.15 \mathrm{~cm}$ per year; therefore, older patients and those who have hypertension must be carefully followed-up and should be informed about the symptoms of aortic dissection. According to the ACC/AHA guidelines, patients with a dilated aortic root or an ascending aorta $>5.0 \mathrm{~cm}$, or if the rate of increase in diameter $>0.5 \mathrm{~cm}$ per year, should undergo simultaneous AVR and ascending aortic replacement (Table 4 ).

AVR carries a high risk for adverse events and poor clinical outcome when associated with LV dysfunction. In patients with functional class NYHA III-IV after aortic replacement, the one year mortality increased especially in patients with aortic stenosis (Rothenburger et al., 2003). Based on factors predicting operative mortality, which have been identified form large series of patients undergoing heart-valve surgery, The Task Force on the Management of Valvular Heart Disease of the European Society of Cardiology proposed risk classification scores for this group of patients (Vahanian et al., 2007) (Table 5).

For high-risk patients to undergo conventional novel methods including aortic balloon valvulotomy or transfemoral valve implantation may be helpful. This method reduced oneyear mortality from $50.7 \%$ in the standard therapy group to $30.7 \%$ in transcatheter aorticvalve implantation group (Leon et al., 2010). A patient considered inoperable should be treated orally with angiotensin converting enzyme (ACE) inhibitors, diuretics, and digitalis. In patients with depressed LV associated with pulmonary congestion and atrial fibrillation, diuretics and digitalis may be used with the understanding that in some cases intensive hemodynamic monitoring is needed. Patients with aortic root dilatation $>4.0 \mathrm{~cm}$ who are not candidate for surgical treatment should be given $\beta$-adrenergic blocking agents.

\section{Case presentations}

\section{Case 1}

\section{History}

- $\quad$ 42- year- old man referred for chest pain and shortness of breath.

- No previous cardiovascular disease

- CAD risk factors present: smoking, hypertension.

\section{Physical examination}

- $\quad$ BP: $140 / 80 \mathrm{mmHg}$, Hr: 64/min

- Arterial pulse is small and rises slowly, "parvus et tardus"

- Heart rhythm regular, fourth heart sound (S4), systolic murmur heard at the base of the heart Gr. 4/6

\section{Other diagnostic procedures}

- $\quad$ ECG: sinus rhythm, Hr: 64/min, biphasic T in D2, D3, AVF, ST segment depression for $0.5 \mathrm{~mm}$ in V5 and V6 with biphasic T.

- TTE: cardiac chambers with normal dimensions, EF: 55\%, aortic valve is bicuspid with vertical commissure, cusps are unequal, aortic valve area: $1.85 \mathrm{~cm}^{2}, \mathrm{~V}$ mean: $131 \mathrm{~cm} / \mathrm{s}$, VTI: $41.9 \mathrm{~cm}$, Mean pressure gradient: $8 \mathrm{mmHg}$, aorta: $2.90 \mathrm{~cm}$, (Figure 2 and 3).

- TEE: Bicuspid aortic valve with vertical commissure, cusps are unequal, aortal regurgitation (Figure 4).

- Coronary angiography: normal coronary arteries. 


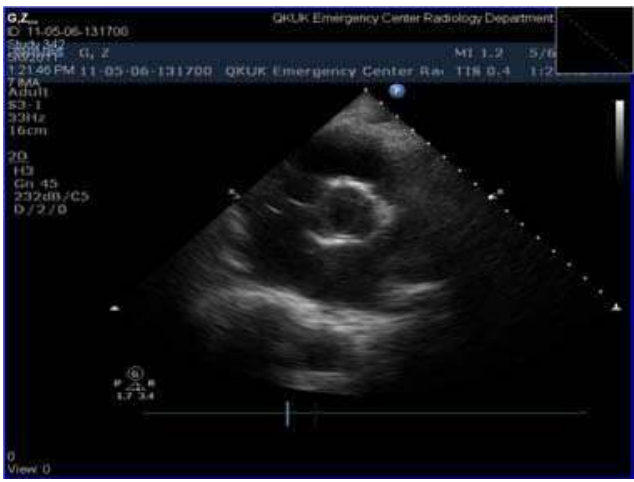

(a)

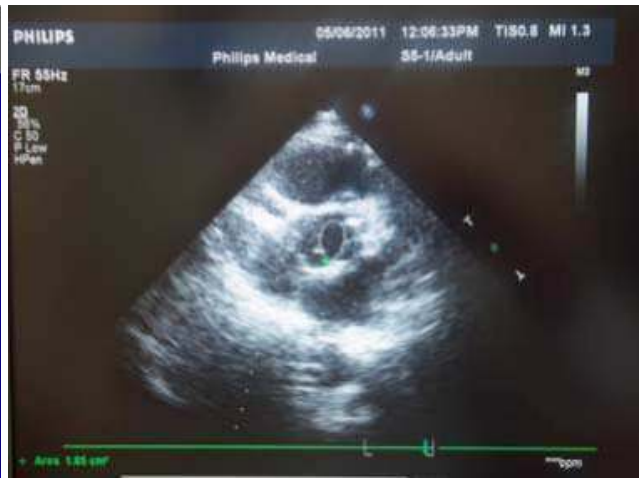

(b)

Fig. 2. TTE: (a) Parasternal short axis view: BAV during systole, (b) Parasternal short axis view: aortic valve area

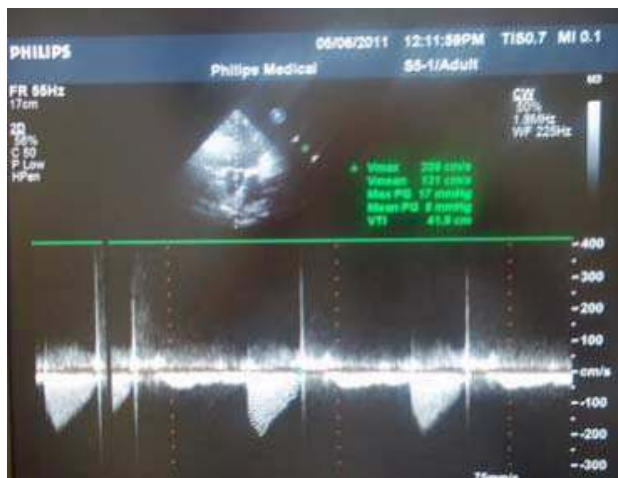

(a)

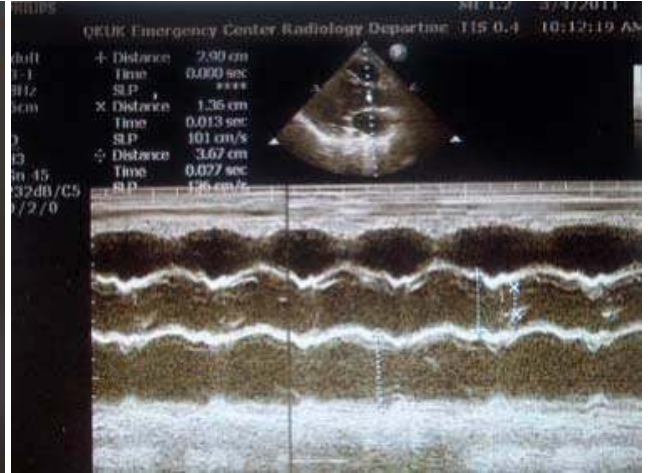

(b)

Fig. 3. TTE: (a) Normal haemodinamic parameters , (b) Parasternal long axis view: Aortic diameter

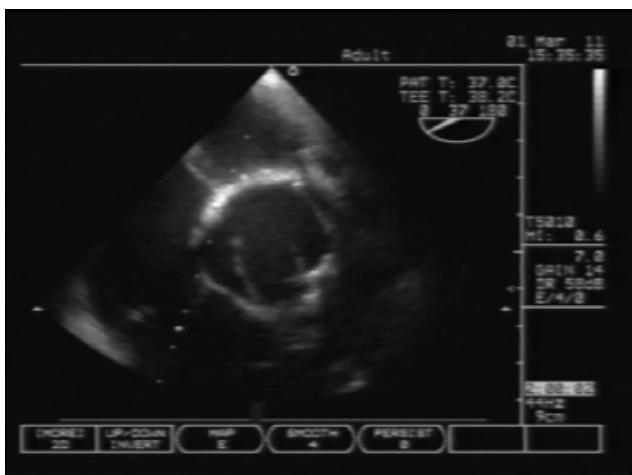

(a)

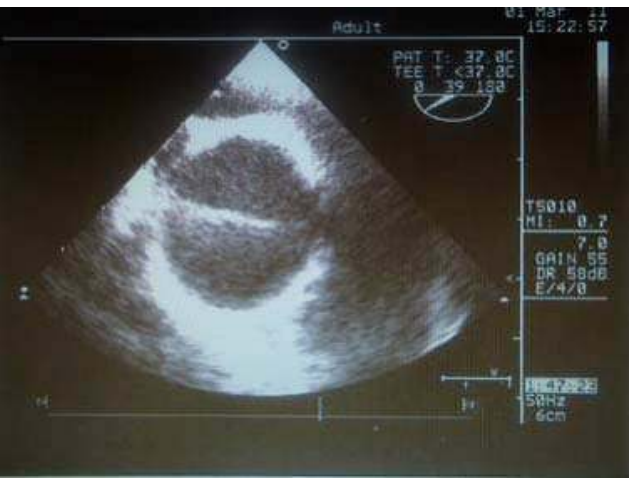

(b) 


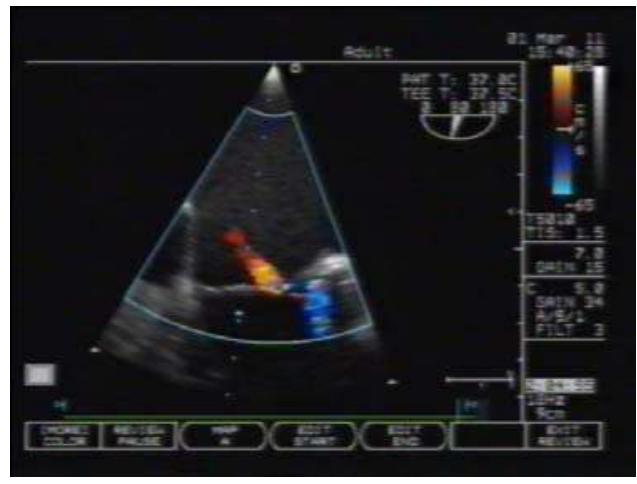

(c)

Fig. 4. TEE: (a) Short axis view: BAV during systole, (b) Short axis: BAV during diastole, (c) Aortic regurgitation

\section{Comments}

- Aortic valve replacement was not indicated in this patient because has no more symptoms, valve area is $1.85 \mathrm{~cm}^{2}$, aortic dimensions are normal, and LV systolic function is normal at rest $(\mathrm{EF}>50)$

\section{Treatment}

- Prescribed ACE inhibitor, endocarditis prophylaxis therapy, recommended serial evaluation using echocardiograpy.

\section{Case 2}

\section{History}

- $\quad$ 57- year- old man referred for chest pain, shortness of breath and syncope.

- No previous cardiovascular disease.

- No CAD risk factors present.

\section{Physical examination}

- $\quad$ BP: $120 / 80 \mathrm{mmHg}, \mathrm{Hr}: 85 / \mathrm{min}$.

- Arterial pulse in apex is normal while in carotid artery is small.

- Heart rhythm iregular, soft systolic murmur heard at the base of the heart and radiated at the apex.

\section{Other diagnostic procedures}

- $\quad$ ECG: atrial fibrillation, Hr: 85/min, ST segment depression for 0.5mm in DI, AVL, V2 -V6.

- TTE: Left cardiac chambers enlarged especially LA,

EF: $45 \%$, aortic valve is artificial, Vel: $1.82 \mathrm{~m} / \mathrm{s}, \mathrm{PG}: 13.2 \mathrm{mmHg}$, incipient dilatation of aorta (Figure 5).

\section{Treatment}

- Before surgical treatment: prescribed $\beta$-adrenergic blocking agents, anti-angina drugs, endocarditis prophylaxis therapy and recommended surgical correction of BAV.

- After surgical treatment: $\beta$-adrenergic blocking agents, anticoagulation therapy, recommended serial evaluation using echocardiography. 


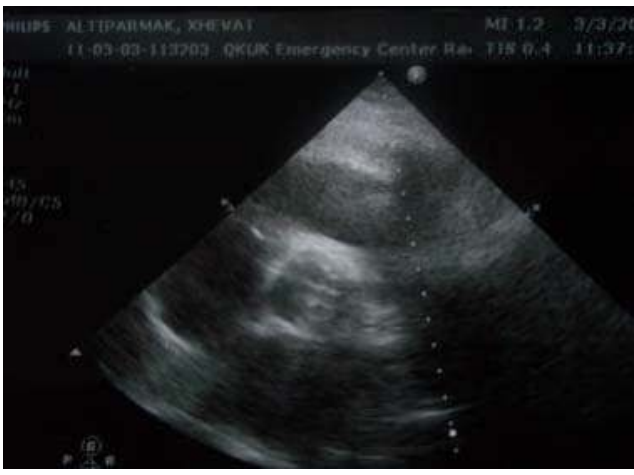

(a)

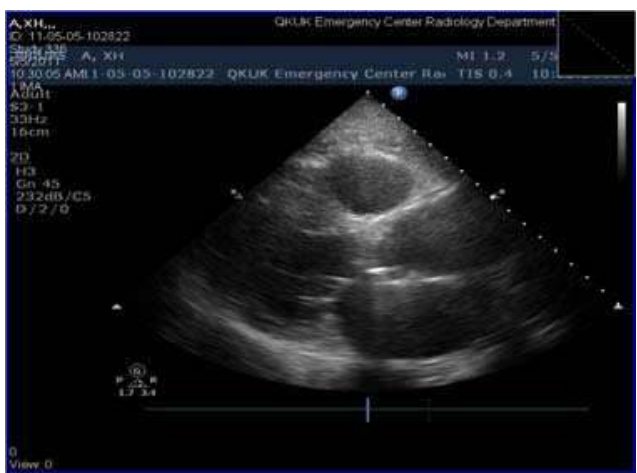

(c)

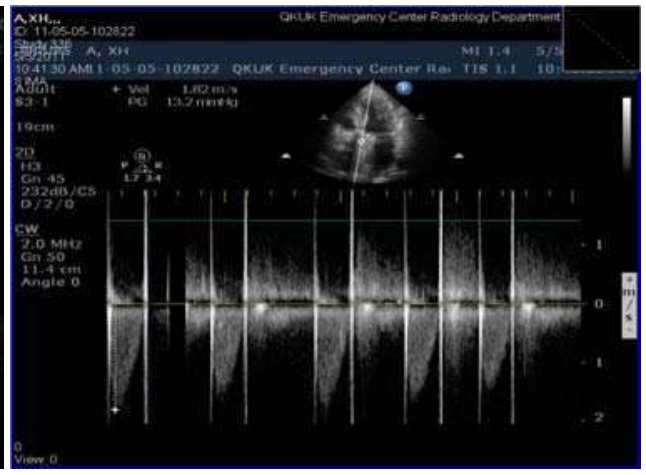

(b)

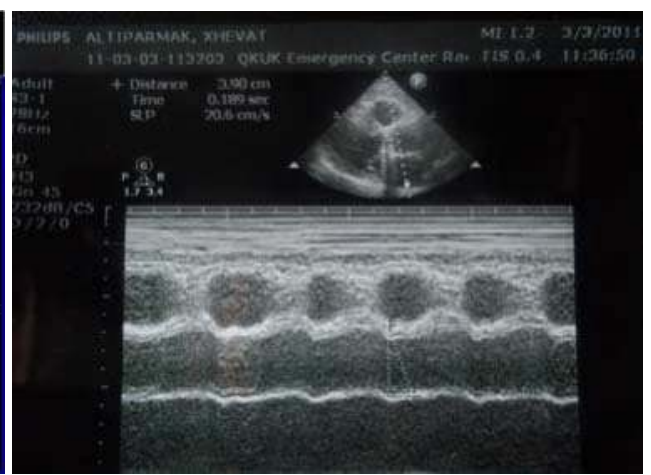

(d)

Fig. 5. TTE: (a) Artificial aortic valve (parasternal short axis view), (b) Apical five chamber view, (c) and (d) Parasternal long axis view: incipient aortic dilatatation and LA enlargement

\section{Comments}

- In this patient we recommended aortic valve replacement because he was symptomatic for several months, he had aortic regurgitation, incipient aortic dilatation, decreased systolic function at rest (EF> $45 \%)$.

- After surgical treatment, patient remained stable and without any postoperative complication.

\section{References}

Abbott, M. (1928) Coarctation of the aorta of adult type; II. A statistical study and historical retrospect of 200 recorded cases with autopsy, of stenosis or obliteration ofdescending arch in subjects above age of two years. Am Heart J, 3:574-618.

Alegret, J., Palazon, O., Duran, I. \& Vernis, J. (2005) Aortic valve morphology definition with transthoracic combined with transesophageal echocardiography in a population with high prevalence of bicuspid aortic valve. Int J Cardiovasc Imaging 21, 213-217.

Andelfinger, G., Tapper AR., Welch, RC.,Vanoye, CG., George, AL. \& Benson, W. (2002) KCNJ2 mutation results in Andersen syndrome with sex-specific cardiac and skeletal muscle phenotypes. Am J Hum Genet 71,663-668. 
Berisha, B., Krasniqi, X., Thaqi, A., Gashi, M \& Kocinaj, D. (2009) Single ventricle, bicuspid aorta and interatrial wall aneurysm as a rare adult congenital heart disease: a case report. Cases Journal, 2:109.

Bonow, RO., Carabello, BA., Kanu, C., et al. (2006) ACC/AHA 2006 guidelines for the management of patients with valvular heart disease: a report of the American College of Cardiology/American Heart Association. Circulation 114,e84-e231

Boughner, DR \& Roach, MR. (1971) Effect of low frequency vibration on the arterial wall. Circ Res, 29:136.

Caruthers, SD., Lin, SJ., Brown, P., Watkins, MP., Williams, TA., Katherine, A. Lehr \& Samuel A. Wickline, SA. (2003) Practical Value of Cardiac Magnetic Resonance Imaging for Clinical Quantification of Aortic Valve Stenosis: Comparison With Echocardiography. Circulation 108, 2236-2243.

Coady, MA., Rizzo, JA., Hammond, GL., et al. (1997) What is the appropriate size criterionfor resection of thoracic aortic aneurysms? J Thorac Cardiovasc 113,476-91.

Cripe, L., Andelfinger, G., Martin, LJ., Shoner, K\& Benson W. (2004) Bicuspid aortic valve is heritable. J Am Coll Cardiol 44,138-43.

Duran, A.C., Frescura, C., Sans-Coma, V., Angelini, A., Baso, C. \& Thiene, G. (1995) Bicuspid aortic valves in hearts with other congenital heart disease. J Heart Valve Dis 4, 581-90.

Eisenberg, LM\& Markwald, RR. (1995) Molecular regulation of atrioventricular valvuloseptal morphogenesis. Circ Res 77,1-6.

Emmanuel, R., Withers, R., O'Brien, K., Ross, P and Feizi, O.,. (1978) Congenitally bicuspid aortic valves, clinicogenetic study of 41 families. Br Heart J 40,1402-7.

Espinal, M., Fuisz, AR., Nanda NC., Aaluri SR., Mukhtar, O \& Sekar PC. (2000) Sensitivity and specificity of transesophageal echocardiography for determination of aortic valve morphology. Am Heart J 139,1071-6.

Fedak PW, Verma S, David TE., Leask Rl, Weisel, RD \& Butany J. (2002) Clinical and pathophysiological implications of a bicuspid aortic valve. Circulation 106,900-4.

Garg, V., Muth, AN., Ransom, JF., Schluterman, MK., Barnes, R., King, IN., Grossfeld, PD \& Srivatava D. (2005) Mutations in NOTCH1 cause aortic valve sdisease. Nature, 437:270-274.

Gelb, BD., Zhang, J., Sommer, RJ., Wasserman, JM., Reitman, MJ \& Willner, JP.(1999) Familial patent ductus arteriosus and bicuspid aortic valve with hand anomalies: a novel heart-hand syndrome. Am J Med Genet 19,87:175-9.

Hallidie-Smith, KA. \& Karas S.(1988) Cardiac anomalies in Williams-Beuren syndrome. Arch Dis Child. 63, 809-13.

Hastreiter, AR., Oshima, M., Miller, RA., Lev, M. \& Paul, MH. (1963) Congenital aortic stenosis syndrome in infancy. Circulation 28,1084 -95.

Hoffman, JI. (1990). Congenital heart disease: incidence and inheritance. Pediatr Clin North Am 37:25-43.

Hoffman, JI. \& Kaplan, S. (2002) The incidence of congenital heart disease. J Am Coll Cardiol 39:1890-1900

Iung, B., Gohlke- Barwold, C., Tornos, P., Tribouilloy, C., Hall, R., Butchart, E \& Vahanaian, A . (2003) Recommendations on the management of the asymptomatic patient with valvular heart disease. Eur Heart J 23,1252-1266.

Julius, BK., Spillmann, M., Vassalli, G., Villari, B., Eberli, FR and Hess OM. Angina pectoris in patients with aortic stenosis and normal coronary arteries: mechanisms \& pathophysiological concepts. (1997) Circulation 95,892-898.

Kappetein A.P., Gittenberger-de Groot A.C., Zwinderman A.H., Rohmer, J., Poelmann, RE. \& Huysmans HA. (1991) The neural crest as a possible pathogenetic factor in 
coartation of the aorta and bicuspid aortic valve . J Thorac Cardiovasc Surg 102,830836.

Komuro, I., Kaida, T., Shibazaki, Y., Kurabayashi, M., Katoh, Y., Hoh, E., Takaku, F \& Yzaki Y.(1990) Stretching cardiac myocytes stimulates protooncogene expression. J Biol Chem, 265:3595.

Komuro, I., Katoh, Y., Kaida, T., Shibazaki, Y., Kurabayashi, M., Hoh, E., Takaku, F. \& Yzaki, Y. (1991) Mechanical loading stimulates cell hypertrophy and specific gene expression in cultured rat cardiac myocytes: possible role of protein kinase C activation. J Biol Chem 266,1265-1268.

Leon, MB., Smith, CR., Mack, M., Miller, DC., Moses, JW., Svensson, LG., et al. (2010) PARTNER Trial Investigators. Transcatheter aortic-valve implantation for aortic stenosis in patients who cannot undergo surgery. N Engl J Med 363, 1597-607.

Lim, MK., Hanretty, K., Houston, AB., Lilley, S., \& Murtagh, EP. (1992) Intermittent ductal patency in healthy newborn infants: demonstration by colour Doppler flow mapping. Arch Dis Child. 67,1217-1218.

Mandorla, S. (1990) The ductus arteriosus in healthy newborn infants studied by continuous Doppler guided by two-dimensional Doppler color echocardiography. G Ital Cardiol. 20,705-712.

Miller, MJ., Geffner, ME., Lippe, BM., Itami, RM., Kaplan, SA., Disesa, TG., Isabel-Jones, JB \& Friedman, WF. (1983) Echocardiography reveals a highincidence of bicuspid aortic valve in Turner syndrome. J Pediatr 102,47-50.

Michelena, HI., Desjardins, VA., Avierinos, JF., Ruso, A., Nkomo, VT., Sundt, TM., Pellikka, PA., Tajik, J \& Enriques-Sarano, M . (2008) Natural history of asymptomatic patients with normally functioning or minimally dysfunctional bicuspid aortic valve in the community. Circulation 117,2776-84.

Mitchell, SC. (1957) The ductus arteriosus in the neonatal period. J Pediatr. 51,12-17.

McMillan, WD., Tamarina, NA., Cipollone, M., Johnson, DA., Parker, MA., Perace, WH. (1997) Size matters: the relationship between MMP-9 expression and aortic diameter. Circulation 96,2228-32

Moller, JH., Nakib, A., Eliot, RS \& Edwards JE. (1966) Symptomatic congenital aortic stenosis in the first year of life. J Pediatr 69,728 -34.

Munt, B, Legget, ME, Kraft, CD, Miyake-Hull, CY., Fujioka, M \& Otto, CM . (1999) Physical examination in valvular aortic stenosis: Correlation with stenosis severity and prediction of clinical outcome. Am Heart J , 137:298.

Nakamoto, S., Saga, T., \& Shinohara, T. (2003) Williams syndrome associated with complete atrioventricular septal defect. Heart, 89:e15.

Nataatmadja, M., West, M., West, J., Summers, K., Walker, P., Nagata, M \& Watanabe, T. (2003) Abnormal extracellular matrix protein transport associated with increased apoptosis of vascular smooth muscle cells in Marfan syndrome and bicuspid aortic valve thoracic aortic aneurysm. Circulation 108, II329-II334.

Neumayer, U., Stone, S. \& Somerville, J. (1998) Small ventricular septal defects in the adult. Eur Heart J 9, 1573-82.

Nishimura, RA., ta al. (2008) ACC/AHA 2008 Guideline Update on Valvular Heart Disease: Focused Update on Infective Endocarditis. J Am Coll Cardiol 52,676-685.

Oppenheimer- Dekker, A., Gittenberger -de Groot, AC., Bartelings, MM., Wenink, AC., Moene, RJ., \& van der Haerte, JJ. (1985) Abnormal architecture of the ventricles in hearts with an overriding aortic valve and a perimembranous ventricular septal defect ("Eisenmenger VSD"). Int J Cardiol. 9,341-55. 
Pellika, PA., Sarano, ME., Nishimura, RA., Malouf, JF., Bailey, KR., Scott, CG., Barnes, ME \& Tajik, J. (2005) Outcome of 622 adults with asymptomatic, hemodinamically significant aortic stenosis during prolonged follow-up. Circulation 111,3290-3295.

Pouleur, A., Waroux, JB., Pasquet, A., Vanoverschelde, J. \& Gerber, B. (2007) Aortic valve area assessment: multidetector CT compared with cine MR imaging and transthoracic and transesophageal echocardiography. Radiology 244,745-754.

Quinones, MA., Otto, CM., Stoddard, M., Waggoner, A., \& Zoghbi, WA. (2002) Doppler Quantification Task Force of the Nomenclature Standards Committee of the American Society of Echocardiography.Recommendations for quantification of Doppler echocardiography: a report from the Doppler Quantification Task Force of the Nomenclature and Standards Committee of the American Society of Echocardiography. J Am Soc Echocardiogr 15,167-184.

Reller, MD., Ziegler, ML., Rice, MJ., Solin, RC and McDonald, RW. (1988) Duration of ductal shunting in healthy preterm infants: an echocardiographic color flow Doppler study. J Pediatr.112,441-446

Roberts WC. (1970) The congenitally bicuspid aortic valve. A study of 85 autopsy cases. Am J Cardiol 26,72-83.

Roques F, Nashef SA, Michel P, Gauducheau E, de Vincentiis C, Baudet E, Cortina J, David M, Faichney A, Gabrielle F, Gams E, Harjula A, Jones MT, Pintor PP, Salomon R, Thulin L. (1999) Risk factors and outcome in European cardiac surgery: analysis of the EuroSCORE muntinational database of 19030 patients. Eur J Cardiothorac Surg 15, 816-822; discussion 822-823

Rothenburger, M., Dreber, K., Tjan, T., Schmidt, C., Schmid, C., Wichter, T., Scheld, HH. \& Dewick, M. (2003) Aortic valve replacement for aortic regurgitation and stenosis, in patients with severe left ventricular dysfunction . Eur J of Cardiothorac Surgery 23,703-709.

Sabet, HY., Edwards, WD., Tazelaar, HD \& Daly, RC.(1999) Congenitally bicuspid aortic valves: a surgical pathology study of 542 cases (1991 through 1996) and a literature review of 2,715 additional cases. Mayo Clin Proc Jan 74,14-26.

Sachdev, V., Matura, LA., Sidenko, S., Ho, VB., Arai, AE., Rosing, DR. \& Bondy, CA. (2008) Aortic valve disease in Turner syndrome. J Am Coll Cardiol 51,1904-9.

Sans-Coma, V., Fernandez, B., Duran, AC., Thiene, G., Arque, JM., Munoz, CR., \& Cardo, M. (1996) Fusion of valve cushions as a keyfactor in the formation of congenital bicuspid aortic valves in Syrian hamsters. Anat Rec 244,490-498.

Schang, SJ., Pepine, CJ. \& Bemiller, CR. (1975) Anomalous coronary artery origin and bicuspid aortic valve. Vasc Surg, 9, 67-72.

Sugayama, SM., Moises, RL., Wagenfur, J, Ikari, NM., Abe, KT, Leone, C., Silva, CA., Chauffaille, M\& Kim, CA . (2003) Williams-Beuren syndrome:cardiovascular abnormalities in 20 patients diagnosed with fluorescent in situ hybridization. Arq Bras Cardiol 81,462-73.

Tzemos, N., Therrien, J., Yip, J., Thanassoulis, G., Tremblau, S., Jamorski, MT., Webb, GD \& Siu, SC. (2008) Outcomes in adults with bicuspid aortic valves. JAMA 300,1317-25.

Vahanian A, Baumgartner H, Bax J et al. (2007) Guidelines on the management of valvular heart disease. The Task Force on the Management of Valvular Heart Disease of the European Society of Cardiology . European Heart Journal 28, 230-268

Ward, C. (2000) Clinical significance of the bicuspid aortic valve. Heart 83,81-85

Zoghbi, WA., Enriquez-Sarano, M., Foster, E., et al. (2003) Recommendations for evaluation of the severity of native valvular regurgitation with two-dimensional and Doppler echocardiography. J Am Soc Echocardiogr 16, 777-802. 


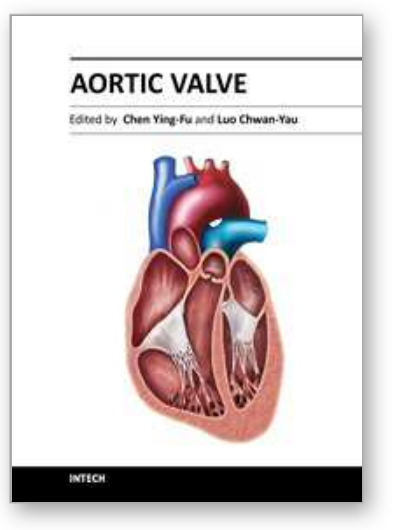

\author{
Aortic Valve \\ Edited by Prof. Chen Ying-Fu
}

ISBN 978-953-307-561-7

Hard cover, 350 pages

Publisher InTech

Published online 09, December, 2011

Published in print edition December, 2011

Much has evolved in the field of aortic valve disease because of the increase in knowledge in the last decade, especially in the area of its management. This book "Aortic Valve" is comprised of 18 chapters covering basic science, general consideration of aortic valve disease, infective endocarditis, aortic sclerosis and aortic stenosis, bioprosthetic valve, transcatheter aortic valve implantation and a special section on congenital anomalies of the aortic valve. We hope this book will be particularly useful to cardiologists and cardiovascular surgeons and trainees. We also believe that this book will be a valuable resource for radiologists, pathologists, cardiovascular anesthesiologists, and other healthcare professionals who have a special interest in treating patients with aortic valve disease. We are certain that information in this book will help to provide virtually most new areas of aortic valve disease that will be employed in the current era.

\title{
How to reference
}

In order to correctly reference this scholarly work, feel free to copy and paste the following:

Blerim Berisha, Xhevdet Krasniqi, Dardan Kocinaj, Ejup Pllana and Masar Gashi (2011). Bicuspid Aortic Valve, Aortic Valve, Prof. Chen Ying-Fu (Ed.), ISBN: 978-953-307-561-7, InTech, Available from: http://www.intechopen.com/books/aortic-valve/bicuspid-aortic-valve

\section{INTECH}

open science | open minds

\section{InTech Europe}

University Campus STeP Ri

Slavka Krautzeka 83/A

51000 Rijeka, Croatia

Phone: +385 (51) 770447

Fax: +385 (51) 686166

www.intechopen.com

\section{InTech China}

Unit 405, Office Block, Hotel Equatorial Shanghai

No.65, Yan An Road (West), Shanghai, 200040, China 中国上海市延安西路65号上海国际贵都大饭店办公楼405单元

Phone: +86-21-62489820

Fax: $+86-21-62489821$ 
(C) 2011 The Author(s). Licensee IntechOpen. This is an open access article distributed under the terms of the Creative Commons Attribution 3.0 License, which permits unrestricted use, distribution, and reproduction in any medium, provided the original work is properly cited. 